\section{Apolipoprotein A-II}

\author{
K. J. Lackner ${ }^{1}$ und D. Peetz ${ }^{2}$ \\ ${ }^{1}$ Institut für Klinische Chemie und Laboratoriumsmedizin, \\ Universitätsmedizin Mainz, Mainz, Deutschland \\ ${ }^{2}$ Institut für Labormedizin, Helios Klinikum Berlin-Buch, \\ Berlin, Deutschland
}

\section{Synonym(e) ApoA-II}

Englischer Begriff apolipoprotein A-II

Definition Strukturprotein der HDL. Nach ApoA-I das Apolipoprotein der High Density Lipoproteine (HDL; s. > High Density Lipoprotein) mit der höchsten Serumkonzentration.

Struktur Homodimer aus 2 identischen 77 Aminosäuren langen Peptiden, die über eine Disulfidbrücke kovalent verknüpft sind; teilweise glykosyliert.

Molmasse Monomer $8,7 \mathrm{kDa}$.

Synthese - Verteilung - Abbau - Elimination ApoA-II wird vorwiegend in der Leber, aber auch im Dünndarm als 100 Aminosäuren langes Präproprotein synthetisiert. Kotranslational wird ein 18 Aminosäuren langes Signalpeptid, posttranslational aber fast ausschließlich intrazellulär ein 5 Aminosäuren langes Propeptid abgespalten. ApoA-II ist zum größten Teil an HDL gebunden; wenig ApoA-II wird auch in $>$ Chylomikronen und VLDL gefunden.

Halbwertszeit 3,5-5 Tage.
Funktion - Pathophysiologie Die physiologische Funktion von ApoA-II ist unklar. Ein vollständiger Mangel führt zu keinem erkennbaren klinischen Phänotyp. ApoA-II moduliert die Aktivität der hepatischen Lipase ( $\triangleright$ Lipase, hepatische) und der $>$ Lecithin-Cholesterin-Acyltransferase (LCAT).

Untersuchungsmaterial - Entnahmebedingungen Serum, EDTA- oder Heparinplasma.

Analytik Immunturbidimetrie, Immunnephelometrie, - Enzyme-linked Immunosorbentassay (nur bei sehr niedrigen Konzentrationen).

Konventionelle Einheit $\mathrm{mg} / \mathrm{dL}$.

Internationale Einheit $\mathrm{g} / \mathrm{L}$.

Umrechnungsfaktor zw. konv. u. int. Einheit 1:100.

Referenzbereich - Erwachsene $20-40 \mathrm{mg} / \mathrm{dL}$ (nur orientierend, da stark methodenabhängig).

Referenzbereich - Kinder S. Erwachsene.

Indikation Bestimmung ist in seltenen Fällen für die Diagnostik von HDL-Mangelsyndromen sinnvoll.

Diagnostische Wertigkeit Von Ausnahmen abgesehen gering.

\section{Literatur}

Schwandt P, Richter O, Parhofer KG (2007) Handbuch der Fettstoffwechselstörungen, 3. Aufl. Schattauer Verlag, Stuttgart 